\title{
Laparoscopic Groin Hernia Repair with TAPP: Experience at a Tertiary Level Hospital
}

\author{
Srijan Malla', Jyoti Rayamajhi', Pawan Singh Bhat ${ }^{1}$, Bishwo Ram Amatya ${ }^{2}$ and
}

\section{Sushil Bahadur Rawal}

\begin{abstract}
${ }^{1}$ Department of Surgery, Nepalese Army Institute of Health Sciences, Shree Birendra Hospital, Chhauni, Kathmandu, Nepal

${ }^{2}$ Department of Anesthesiology, Nepalese Army Institute of Health Sciences, Shree Birendra Hospital, Chhauni, Kathmandu, Nepal
\end{abstract}

\begin{tabular}{l} 
ABSTRACT \\
Introduction: Groin hernia represents a significant volume of workload at the department of surgery of \\
our institute constituting about $25 \%$ of total general surgical operations annually. Regular laparoscopic \\
repair is now being done at the hospital. Hence, a retrospective study was performed to assess safety, \\
feasibility, return to work and associated complication during the learning curve. \\
Methods: A single institution, single unit retrospective study of all TAPP hernia repair performed at the \\
department of surgery from Dec 2016 to Nov 2017 was done. Data of all patients undergoing TAPP were \\
obtained from a proforma attached to the case file during patients' admission and retrospectively \\
analyzed. \\
Results: A total number of 41 patients underwent the surgery including three bilateral hernias giving a \\
total of 44 TAPPs being performed during the study period. Age group varied from 19 years to 72 years \\
and a male dominance with 40 males to one female. Four patients underwent surgery for recurrent hernia \\
following open surgery. Per operative findings of indirect hernia was noted in 39 , direct in four and \\
femoral in the only female patient. Duration of surgery ranged from 47 minutes to 128 minutes with \\
progressively decreasing time in the second half of the study period. Complications encountered in the \\
post-operative period were seroma in four patients, peritonitis in one and recurrence in one patient. \\
Patients were discharged in median two days with the serving soldiers sent back to their respective units \\
in median seven days. \\
Conclusions: Laparoscopic repair of groin hernias can safely be carried out in our settings with the TAPP \\
method with all the established advantages of a minimal access surgery. \\
\hline
\end{tabular}

Correspondence:Srijan Malla, Department of Surgery, Nepalese Army Institute of Health Sciences, Shree Birendra Hospital, Chhauni, Kathmandu, Nepal. Email: srijanmalla@gmail.com

DOI: http://dx.doi.org/10.3126/mjsbh.v17i1.18693

Submitted on: 2017-12-11

Accepted on: 2018-02-12 


\section{INTRODUCTION}

Groin hernia repair is one of the most common general surgical operations performed worldwide with more than 20 million surgeries around the world annually. ${ }^{1}$ The surgery for groin hernias has continuously evolved from the time Marcy attempted the reduction of hernia sac and closure with carbolized catgut sutures. ${ }^{2}$ Subsequently, Lichtenstein's tension free mesh repair established itself as the gold standard surgery. ${ }^{3}$

With the advent of minimal access surgery, laparoscopic hernia surgery in the form of Transabdominal Pre Peritoneal repair (TAPP) or Totally Extra Peritoneal repair (TEP) has challenged the gold standard. Currently laparoscopic surgery is the recommended procedure for bilateral/recurrent groin hernias. In unilateral groin hernia, it is recommended as one of the treatment options. ${ }^{4}$

At the department of surgery of the tertiary care centre in Nepal, where the study was conducted, groin hernia represents a significant volume of workload constituting about $25 \%$ of total general surgical operations annually. Regular laparoscopic surgery for groin hernias was recently started at the hospital. Hence, a retrospective study was performed to assess safety, feasibility and associated complication during the learning curve.

\section{METHODS}

This is a single institution, single unit retrospective review of prospectively maintained database of all patients undergoing TAPP hernia repair at the hospital. The study period was from Dec 2016 to Nov 2017. All adult patients undergoing TAPP repair for groin hernias were included in the study. Patients undergoing open hernia repair were excluded. Similarly congenital hernias, obstructed and incarcerated hernias were also excluded.
All cases were operated under general anaesthesia. A $16 \mathrm{Fr}$ Foleys catheter was inserted after induction, and removed post procedure except in those above 60 years of age, in whom it was kept for 24 hours after surgery. All patients received inj Ceftriaxone $1 \mathrm{gm}$ at induction and repeated 8 and 16 hours post operatively.

Pneumoperitoneum was created by open method and $10 \mathrm{~mm}$ camera port placed just above the umbilicus. Two $5 \mathrm{~mm}$ lateral working ports were placed at midclavicular line at the level of the umbilicus. Preperitoneal space was dissected on the side of the hernia and the hernial sac reduced. After the dissection, a rolled $10 \times 15 \mathrm{~cm}$ polypropylene mesh was introduced via the $10 \mathrm{~mm}$ port. The mesh was spread to cover the entire myopectineal area on the affected side. In bilateral hernia, both meshes were placed to overlap each other in the midline. The mesh was fixed with tackers on the Cooper's ligament and the peritoneum closed with vicryl 2-0 or tackers.

Oral fluids were allowed after six hours and gradually progressed to normal diet the next day. The patients were usually ready for discharge on post-operative day one. However, due to service requirements, logistical problems, and socioeconomic considerations, the discharges were made much later in serving soldiers. The majority of ex-servicemen and the dependents of serving soldiers were discharged on first post-operative day. The patients were followed up at 1 week and all serving soldiers sent to their respective units with instructions to resume normal duties after seventh postoperative day.

Patients admitted in the general and minimal access surgery unit with the diagnosis of groin hernia were offered laparoscopic surgery. At the time of admission, preoperative data of patients undergoing laparoscopic groin hernia surgery were recorded on 
Table 1: Patient Characteristics and Clinical Profile

\begin{tabular}{|c|r|}
\hline Patient Characteristics & \multicolumn{1}{c|}{ Total } \\
\hline Age (years) & \\
\hline Mean \pm SD & $46.7 \pm 16.7$ \\
\hline Range & $19-72$ \\
\hline Male & \\
\hline Female & $40(97.6 \%)$ \\
\hline Presenting Complaints & $1(2.4 \%)$ \\
\hline Swelling & $41(100 \%)$ \\
\hline Pain & $23(56.1 \%)$ \\
\hline
\end{tabular}

a structured performa including demographic data, duration of symptoms, progression, characteristic features of hernia like side (unilateral or bilateral), type and presence of any complications. Intraoperative data recorded were duration of surgery, type of hernia, intra-operative complication and technique of peritoneal closure. In the postoperative period, complications, need of re-interventions and hospital stay were recorded.

Data obtained were entered in SPSS table and statistical analysis performed using SPSS version 23.0. Results were presented in tables and graphs.

\section{RESULTS}

During the study period of one year, 41 patients underwent laparoscopic groin repair in the form of TAPP. Three patients had bilateral hernias, giving a total of 44 TAPP repairs in the study period. Patient characteristics and their clinical profile are given in table 1 . The mean age of the patients was $46.7 \pm$ 16.7 years. The only female patient in the study group had a femoral hernia. Hernia characteristics are described in table 2. Out of the 44 TAPP repairs, four were performed for recurrent hernias following a previous open repair. The mean
Table 2: Characteristics of hernia

\begin{tabular}{|l|r|}
\hline Characteristics & Total \\
\hline Unilateral & 38 \\
\hline \multicolumn{1}{|c|}{ Right } & 25 \\
\hline \multicolumn{1}{|c|}{ Left } & 13 \\
\hline Bilateral & 3 \\
\hline Total number of TAPP repairs & 44 \\
\hline Primary hernias & 40 \\
\hline Recurrent hernias & 4 \\
\hline
\end{tabular}

operating time for unilateral and bilateral hernias were $72.8 \pm 21 \mathrm{mins}$ and $97.3 \pm 28.9 \mathrm{mins}$ respectively. None of the patients required conversions to open surgery with no significant intra-operative complication encountered during the surgery.

Post-operative morbidity was detected in six patients, with two patients requiring re-exploration. Four patients had seroma, with two managed conservatively with pressure dressing and two requiring aspiration. One patient was detected to have recurrence of the hernia in the first postoperative day and was taken up for open reexploration on the second post-operative day. Operative finding was a rolled up mesh with a peritoneal defect medially. The other patient requiring re-exploration was a 61-year-old male who developed features of peritonitis on the first post-operative morning. Exploratory laparotomy was performed suspecting bowel injury. However, no bowel injury or other significant cause for peritonitis was detected at exploration. The clinical signs of peritonism was probably due to tackers used to close the peritoneum. He was discharged without further complications on the seventh postoperative day. 
Table 3. Intra-operative Factors and Complications

\begin{tabular}{|l|r|}
\hline Characteristics & Total \\
\hline Type of Hernia & \\
\hline Indirect & 39 \\
\hline Direct & 4 \\
\hline Femoral & 1 \\
\hline Mean operating time (mins) & \\
\hline \multicolumn{1}{|c|}{ Unilateral } & $72.8 \pm 21$ \\
\hline \multicolumn{1}{|c|}{ Bilateral } & nil \\
\hline Conversion to open surgery & nil \\
\hline Injury to viscera & nil \\
\hline Injury to major vessels & 28.9 \\
\hline
\end{tabular}

\section{DISCUSSION}

With the advent of minimal access surgery, Ger first reported laparoscopic hernia repair in $1991 .^{5}$ Subsequently, laparoscopic repairs of groin hernia have evolved into two main approaches: Trans Abdominal Pre-Peritoneal (TAPP) pioneered by Arregui ${ }^{6}$ and Totally Extra-Peritoneal (TEP) reported by Dulucq 7 . Initial studies showed higher risks of serious complication rate $^{8}$ and higher recurrence rates. ${ }^{9}$ However with increasing experience, laparoscopic surgery has shown several advantages over open repair in terms of reduced postoperative pain and morbidity, early return to work and usual activities, low recurrence rate and a better quality of life. Thus, laparoscopic inguinal hernia surgery is now the preferred procedure for bilateral and recurrent inguinal hernias and is one of the recommended options for unilateral hernias. ${ }^{10,11}$

Though laparoscopic surgery services in the form of laparoscopic cholecystectomy started at our centre from $2001^{12}$, regular laparoscopic inguinal hernia surgery was started only recently after the
Table 4: Post-operative factors and complications

\begin{tabular}{|l|r|}
\hline Characteristics & \multicolumn{1}{c|}{ Total } \\
\hline Seroma & $4(9.1 \%)$ \\
\hline Early recurrence & $1(2.3 \%)$ \\
\hline Peritonism & $1(2.3 \%)$ \\
\hline Median hospital stay & 2 days (1-7) \\
\hline $\begin{array}{l}\text { Median days to return to work } \\
\text { (serving soldiers) }\end{array}$ & 7 days \\
\hline
\end{tabular}

acquisition of advanced laparoscopic set up in the hospital. TAPP approach was preferred due to its shorter learning curve compared to TEP. ${ }^{13}$ Although the surgeries performed in this study, remain within the learning curve of the operating surgeon, the results compare favorably with other studies.

The mean age of the patients in the current study was $46.7 \pm 16.7$ years, is consistent with a randomized multicenter trial (SCUR Hernia Repair Study) which also showed that most hernia occurred in patients above 45 years of age. ${ }^{14}$ Only one female patient out of the 41 patients in this study indicates a male preponderance, which probably has been amplified, as the study was performed in an army hospital. Similar study from Army College of Medical Sciences, Base Hospital Delhi in 434 patients reported only seven female patients (1.7\%). ${ }^{15}$ A 10-year study of abdominal hernia in the US Armed Forces reported incidence rate of inguinal hernias among males was six times the rate among females. However, incidence rates of femoral hernia was higher among females than males. ${ }^{16}$ Incidentally, the female patients in our study had the only femoral hernia out of 44 groin hernias included in this study.

Outcomes in our study compares quite favourably with other studies. There were no intra-op complications, no conversions, and minor post-op complications in $9.1 \%$, major complication in $2.3 \%$ 
and early recurrence in $2.3 \%$. A similar study from Eastern Nepal, reported seroma in $4 \%$, conversion in $4 \%$ and recurrence in $2 \%$ cases. ${ }^{17} \mathrm{~A}$ large prospective multi-center randomized controlled trial (RCT) in 2004 among 2164 patients reported the intraoperative, postoperative and long-term complications to be $4.8 \%, 24.6 \%$ and $18 \% .{ }^{18}$ Another similar RCT in 2008 among 365 patients reported similar complications to be $2 \%, 16 \%$ and $18 \%$ respectively. 19 There were no conversions in our study. A 2011 study by Swadia reported a conversion of $1.2 \%$ in their series of 1539 surgeries. ${ }^{20}$ Dulucq et al., in 2009 also reported a conversion of $1.2 \%$ in their series of 3100 repairs. ${ }^{21}$

The operative times reported by large series show a large variation, with significant decrease in operating time after the first 30-50 cases. A 10-year prospective study of 1058 TAPP repair showed a mean operating time of $60.15 \pm 24.27$ minutes with a reduction in time to $46.64 \pm 19.23$ minutes in the last three years. ${ }^{22}$ Similarly, a population based 12 year analyses of endoscopic hernia repair showed a mean operating time of 59.0 minutes in 1095 TAPP repair.23 Our operating time is understandably longer (unilateral $72.8 \pm 21$, bilateral $97.3 \pm 28.9$ ), as we are still in the learning curve of the procedure.

\section{CONCLUSIONS}

Though laparoscopic hernia repair have a steep learning curve, the TAPP method appears to be suitable in our setting, as it can safely be carried out with minimum complications with all the established advantages of a minimal access surgery. However, a long term follow up is recommended to assess delayed recurrence and chronic groin pain.

To cite this article: Malla S, Rayamajhi J, Bhat PS, Amatya BR, Rawal SB. Laparoscopic Groin Hernia Repair with TAPP: Experience at Nepal Army Hospital. MJSBH. 2018;17(1):31-7.

Conflict of Interest: None declared

\section{REFERENCES}

1. Keller J, Muo C-H, Lan Y-C, Sung F-C, Lo F-E, Chiang K-Y et al. A nation-wide population-based study of inguinal hernia repair incidence and age-stratified recurrence in an Asian population. Hernia. 2015;19(5):735-40.

DOI: https://doi.org/10.1007/s10029-015-1359-4 PMid:25739714

2. Marcy H. A new use of carbolized cat gut ligatures. Boston Med Surg J. 1871;315-6.

DOI: https://doi.org/10.1056/NEJM187111160852002

3. Lichtenstein IL. Hernia Repair without Disability. St. Louis: CV Mosby; 1970.

4. Miserez M, Peeters E, Aufenacker T, Bouillot JL, Campanelli G, Conze J et al. Update with level 1 studies of the European Hernia Society guidelines on the treatment of inguinal hernia in adult patients. Hernia. 2014;18:151-63. 
5. Ger R. Laparoscopic hernia operation. Chirurg. 1991;62(4):266-70.

PMid:1830542

6. Arregui MR, Davis CD, Yucel O, Nagan RF. Laparoscopic mesh repair of inguinal hernia using a preperitoneal approach: a preliminary report. Surg Laparosc Endosc. 1992;2:53-8.

PMid:1341501

7. Dulucq JL. Treatment of inguinal hernia by insertion of a subperitoneal patch under pre-peritoneoscopy. Chirurgie. 1992;118(1-2):83-5.

PMid:1306431

8. McCormack K. Laparoscopic techniques versus open techniques for inguinal hernia repair. Cochrane Database Syst. Rev. 2003;1:CD001785.

DOI: https://doi.org/10.1002/14651858.CD001785

9. Neumayer L, Giobbie-Hurder A, Jonasson O. Open mesh vs laparoscopic mesh repair of inguinal hernia. N Engl J Med. 2004;350:1819-27.

DOI: https://doi.org/10.1056/NEJMoa040093 PMid:15107485

10. Koninger R, Redecke N, Butters CA. Chronic pain after hernia repair: a randomized trial comparing Shouldice, Lichtenstein and TAPP. Langenbecks Arch Surg. 2004;389:361-5.

DOI: https://doi.org/10.1007/s00423-004-0496-5 PMid:15243743

11. WangWJ, Chen JZ, Fang Q. Comparison of the effects of laparoscopic hernia repair and lichtenstein tension-free hernia repair. J Laparoendosc Adv Surg Tech A. 2013;23:301-5.

DOI: https://doi.org/10.1089/lap.2012.0217 PMid:23573878

12. Malla S, Rawal SB, Giri NK. Laparoscopic Cholecystectomy at Shree Birendra Hospital. MJSBH. 2011;10:15-9.

13. Leibl BJ, Jäger C, Kraft B. Laparoscopic hernia repair -TAPP or/and TEP? Langenbecks Arch Surg. 2005;390(2):77-82.

DOI: https://doi.org/10.1007/s00423-004-0532-5PMid:15711997

14. Johansson B, Hallerback B, Glise H, Anesten B, Smedberg S, Roman J. Laparoscopic mesh versus open preperitoneal mesh versus conventional technique for inguinal hernia repair :a randomized multicenter trial (SCUR Hernia Repair Study). Ann Surg. 1999;230:225-31.

DOI: https://doi.org/10.1097/00000658-199908000-00013ＰMid:10450737

15. Jakhmola CK, Kumar A. Laparoscopic inguinal hernia repair in the Armed Forces: A 5-year single centre study. Med J Armed Forces India. 2015;71(4):317-23.

DOI: https://doi.org/10.1016/j.mjafi.2015.05.005 PMid:26663957

16. O'Donnell FL, Taubman SB. Incidence of abdominal hernias in service members, active component, U.S. Armed Forces, 2005-2014. MSMR. 2016;23(8):2-10.

PMid:27602797 
17. Shakya VC, Sood S, Bhattarai BK, Agarwal CS, Adhikary S. Laparoscopic inguinal hernia repair: a prospective evaluation at Eastern Nepal. Pan Med J. 2014;17:241.

DOI: https://doi.org/10.11604pamj.

18. Neumayer L, Giobbie-Hurder A, Jonasson O, Fitzgibbons Jr R, Dunlop D, Gibbs J et al. Open mesh vs laparoscopic mesh repair of inguinal hernia. N Engl J Med. 2004;350:1819-27.

DOI: https://doi.org/10.1056/NEJMoa040093 PMid:15107485

19. Pokorny H, Klingler A, Schmid T, Fortelny R, Hollinsky C, Kawji R et al. Recurrence and complications after laparoscopic versus open inguinal hernia repair: results of a prospective randomized multicenter trial. Hernia. 2008;12(4):385-9.

DOI: https://doi.org/10.1007/s10029-008-0357-1 PMid:18283518

20. Swadia ND. Laparoscopic totally extra-peritoneal inguinal hernia repair: 9 years' experience. Hernia. 2011;15:273-9.

DOI: https://doi.org/10.1007/s10029-010-0781-x PMid:21290156

21. Dulucq JL, Wintringer P, Mahajna A. Laparoscopic totally extraperitoneal inguinal hernia repair: lessons learned from 3,100 hernia repairs over 15 years. Surg Endosc. 2009;23:482-6.

DOI: https://doi.org/10.1007/s00464-008-0118-3 PMid:18810548

22. Soltés M, Pazinka P, Radonak J. Laparoscopic hernioplasty TAPP in treatment of groin hernia -10 years' experience. Rozhl Chir. 2010;89(6):384-9.

PMid:20731318

23. Gass M, Banz VM, Rosella L, Adamina M, Candinas D, Güller U. TAPP or TEP? Population-based analysis of prospective data on 4,552 patients undergoing endoscopic inguinal hernia repair. World $\mathrm{J}$ Surg. 2012;36(12):2782-6.

DOI: https://doi.org/10.1007/s00268-012-1760-4 PMid:22956012 